\title{
Correction to: Transanal hemorrhoidal dearterialization (THD) for hemorrhoidal disease: a single-center study on 1000 consecutive cases and a review of the literature
}

\author{
Carlo Ratto $^{1}$ Paola Campennì ${ }^{1}$. Francesco Papeo ${ }^{1} \cdot$ Lorenza Donisi $^{1} \cdot$ Francesco Litta $^{1} \cdot$ Angelo Parello $^{1}$
}

Published online: 28 February 2018

○) Springer International Publishing AG, part of Springer Nature 2018

\section{Correction to:}

Techniques in Coloproctology (2017) 21:953-962

https://doi.org/10.1007/s10151-017-1726-5

The article "Transanal hemorrhoidal dearterialization (THD) for hemorrhoidal disease: a single-center study on 1000 consecutive cases and a review of the literature" written by C. Ratto et al. was originally published Online First without open access. After publication in volume 21, issue 12, page 953-962 the author decided to opt for Open Choice and to make the article an open access publication.
Therefore, the copyright of the article has been changed to (c) The Author(s) 2018 and the article is forthwith distributed under the terms of the Creative Commons Attribution 4.0 International License (http://creativecommons.org/licenses/ by/4.0/), which permits use, duplication, adaptation, distribution and reproduction in any medium or format, as long as you give appropriate credit to the original author(s) and the source, provide a link to the Creative Commons license, and indicate if changes were made.

The original article can be found online at https://doi.org/10.1007/ s10151-017-1726-5.

Carlo Ratto

carloratto@tiscali.it

1 Proctology Unit, University Hospital “A. Gemelli”, Catholic University, Largo A. Gemelli, 8, 00168 Rome, Italy 